\title{
Winglets of the eye: dominant transmission of early adult pterygium of the conjunctiva
}

\author{
Frederick Hecht, Mark G Shoptaugh
}

\begin{abstract}
A pterygium, a wing-like thickening, of the bulbar conjunctiva is of environmental interest because it can occur on prolonged exposure to wind and weather. We describe a family with pterygium in two generations without a history of unusual exposure to the elements. There were six females and five males (including a set of male twins) with seven bilateral and four unilateral pterygia. The onset was unique in being in early adulthood, from the late teens through the twenties. This new genetic form can be distinguished by the age of onset from congenital and mid-adult pterygia, which are inherited as autosomal dominant traits. Irrespective of age, the treatment of conjunctival pterygium is surgical excision.
\end{abstract}

The origin of the word pterygium is of some interest. A pterygium is literally a little wing. The ending is Latin because the diminutive of pteryx, which in Greek means wing, passed through modern Latin. The term pterygium has been applied to anomalous anatomical structures that resemble little wings. A webbed neck has been called pterygium colli, a web across the antecubital fossa an antecubital pterygium, and a web across the popliteal fossa a popliteal pterygium.

A pterygium of the conjunctiva looks like a little wing. It is a thickening of the bulbar conjunctiva. The process begins near one corner of the eye, most commonly the inner canthus. The progressive head is

The Genetics Center of Genetrix, Inc, and the Southwest Biomedical Research Institute, Scottsdale, Arizona, and Phoenix Children's Hospital, Phoenix, Arizona, USA. F Hecht, M G Shoptaugh

Correspondence to Dr Hecht, 4134 McGirts Boulevard, Jacksonville, Florida 32210, USA.

Received for publication 28 October 1989

Revised version accepted for publication 19 January 1990. typically fleshy and can infiltrate the cornea and block vision. The red conjunctival neck and body are also characteristic. Surgical excision is curative, although recurrence can take place after surgical removal.

Here we describe the inheritance of pterygium of the conjunctiva in the family of the second author of this report. We also review published reports on the genetics of this condition, which indicate that multiple forms may be heritable as autosomal dominant phenotypes.

\section{The family}

The presence of multiple cases of conjunctival pterygium in this family came to light one day in the Spring of 1989. The second author of this report was talking to the first author, who noticed he was rubbing his left eye which was reddened. In answer to whether he had conjunctivitis, the second author replied, "No. I just had a pterygium removed." The first author then asked, "Does anyone else in your family have a pterygium?" In this way, the family study began. The proband is III. 2 in the figure.

The progenitors of the family, I.1 and I.2, are dead. Nothing is known about their ophthalmological

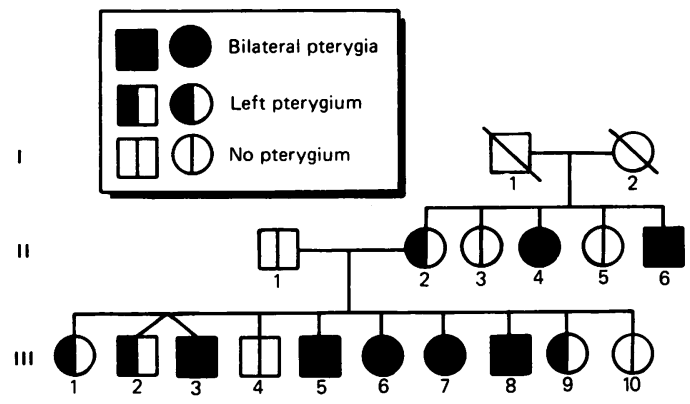

Pedigree of family with early adult onset of pterygium of the conjunctiva. 
condition. They lived in the Midwestern USA and raised their five children there near sea level. Three of these five children developed pterygium of the conjunctiva.

One of the affected children (II.2) married a paediatrician (II.1). They settled and raised their children in the Rocky Mountains. The children now range from 25 to 34 years of age. All but two of the 10 offspring have had conjunctival pterygium.

The family contains a total of 11 members known to have had pterygium. In all cases, the pterygium was located in the inner canthal region. It was unilateral in three cases and bilateral in eight cases.

The sex ratio of affected persons in the family is five males:six females. The affected males include a set of twins who bear an uncanny resemblance to each other but have not had zygosity testing.

The age of onset of pterygium was consistently after adolescence. The earliest onset was in the late teens in one of the twins, III.3, and a singleton brother, III.5. The latest onset was in the index twin, III.2, in his late twenties. The remaining eight affected persons had onset of pterygium in their early to mid twenties.

\section{Discussion}

We do not know whether one of the progenitors, I.1 or I.2, had pterygium, but it can be safely assumed that one of them was carrying the gene for pterygium since they had three affected offspring. Hence, this is a three generation kindred.

The twins, III.2 and III.3, who are thought to be identical, differed as to age of onset and laterality: III. 2 had relatively late onset of left pterygium while III. 3 had earlier onset of bilateral pterygia. Assuming they are identical, this speaks for an influence upon the expression of pterygium by non-genetic factors. These non-genetic factors cannot be wind, weather, or ultraviolet exposure in this family since there is no history of prolonged exposure to wind or weather and the first generation known to contain affected persons (generation II) was raised at a low altitude without increased exposure to ultraviolet light.

\section{AGE OF ONSET}

The age of onset of pterygium of the conjunctiva in the family described here ranged from the late teens to the late twenties. It could therefore be characterised as early adult onset.

\section{Congenital pterygium}

Conjunctival pterygium can occur at any age. Congenital pterygium is rare but has been reported by Jacklin $^{1}$ in 1964 in six members (four females, two males) in a three generation kindred. Murken and
Dannheim ${ }^{2}$ in 1965 concluded that congenital pterygium is a dominant trait with $70 \%$ penetrance. In his Mendelian inheritance in man, McKusick ${ }^{3}$ takes note of these communications and lists congenital pterygium as a possible autosomal dominant trait (MIM 17800).

\section{Early adult pterygium}

The present paper provides the first report, to our knowledge, of the early adult onset of hereditary pterygium. Although there was no evidence for male to male transmission, the vertical transmission and sex ratio are consistent with an autosomal dominant phenotype.

\section{Mid-adult pterygium}

In 1987 , Zhang ${ }^{4}$ reported a three generation family containing 11 members with pterygium of the conjunctiva. Onset ranged from 25 to 46 years with an average of 37 years of age. Male to male transmission was well documented.

\section{GENETICS}

Zhang ${ }^{4}$ reviewed medical publications and found 11 reports of families segregating for conjunctival pterygium. The first report appears to have been in 1893 by Gutierrez-Ponce, as recounted later by Waardenburg.

A tentative proposed classification of hereditary forms of pterygium of the conjunctiva is presented in table 1. We would suggest that these forms are distinct according to age of onset and that all are probably autosomal dominant traits. They may represent alleles at a single locus or genes at distinct loci.

Table 1 Hereditary forms of pterygium of the conjunctiva and cornea.

\begin{tabular}{|c|c|c|c|}
\hline Form & Reference & Inheritance & McKusick No \\
\hline $\begin{array}{l}\text { Congenital } \\
\text { Early adult } \\
\text { Mid-adult }\end{array}$ & $\begin{array}{l}\text { Jacklin' } \\
\text { This report } \\
\text { Zhang }\end{array}$ & $\begin{array}{l}\text { Autosomal dominant } \\
\text { Autosomal dominant } \\
\text { Autosomal dominant }\end{array}$ & $\begin{array}{l}17800 \\
\text { None } \\
\text { None }\end{array}$ \\
\hline
\end{tabular}

Table 2 Environmental factors thought to play a role in pterygium of the conjunctiva and cornea.

\begin{tabular}{ll}
\hline Factors & \multicolumn{1}{c}{ References } \\
\hline Heat, dust, and wind & Hilgers $^{6}{ }^{\text {Duke-Elder, }}{ }^{7}$ Sorsby $^{8}$ \\
Desiccation from dry climate & Hilgers $^{6}$ \\
Decreased lacrimal secretions & Sorsby $^{8}$ \\
Trachoma & Qi $^{9}$ \\
Chronic conjunctivitis & Dhir et al ${ }^{10}$ \\
Oil fumes & Duke-Elder \\
Solar ultraviolet radiation & Sorsby, ${ }^{8}$ Chirambo and Hutt, $^{11}$ \\
& Tarlor ${ }^{12}$ \\
\hline
\end{tabular}


ENVIRONMENTAL FACTORS

There is no doubt that environmental factors can also predispose to pterygium of the conjunctiva. Some of these predisposing environmental factors are listed in table 2 .

MODEL OF GENETIC-ENVIRONMENTAL INTERACTION One might argue that genetic factors are exclusively responsible for the forms of hereditary pterygium of the conjunctiva and cornea listed in table 1 . Conversely, one might hold that the environmental factors listed in table 2 are responsible for pterygium. The most productive model may, however, be to consider pterygium as resulting from genetic-environmental interactions.

Genetic factors would make for susceptibility to pterygium. Environmental factors would then act to influence the expression of pterygium, affect the age of onset in some cases, and determine the degree of penetrance. Note that in congenital pterygium ${ }^{45}$ the penetrance is incomplete. This must reflect the action of environmental factors before birth.

A genetic-environmental interactive model for pterygium is like that proposed for familial hyper- sensitivity to insect stings. ${ }^{13}$ The hypersensitivity is genetic while the insult is environmental from the venom of an insect.

1 Jacklin HN. Familial predisposition to pterygium formation: report of a family. Am F Ophthalmol 1964;57:481-2.

2 Murken JD, Dannheim R. Zur Genetik des Pterygium corneae. Klin Monatsbl Augenheilkd 1965;147:574-9.

3 McKusick VA. Mendelian inheritance in man. Baltimore: Johns Hopkins University Press, 1988.

4 Zhang J-D. An investigation of aetiology and heredity of pterygium. Report of 11 cases in a family. Acta Ophthalmol (Copenh) 1987;65:413-6.

5 Waardenburg JP. Genetics and ophthalmology. Vol 1. Assen: Royal VanGorcum, 1961:267-8.

6 Hilgers JHC. Pterygium: its incidence, heredity and etiology. Am $\mathcal{F}$ Ophthalmol 1960;50:635-44.

7 Duke-Elder S. System of ophthalmology. Vol 8. London: Kimpton, 1965:573-85.

8 Sorsby A, ed. Modern ophthalmology. Vol 4. London: Butterworths, 1972:786-8.

9 Qi XZ. Investigation on etiology of the pterygium. Zhonghua Yanke Zazhi 1966;13:179-82.

10 Dhir SP, Detels R, Alexander ER. The role of environmental factors in cataract, pterygium and trachoma. Am $\mathcal{F}$ Ophthalmol 1967;64:128-35.

11 Chirambo MC, Hutt MSR. Solar keratosis pterygium, and squamous cell carcinoma of the conjunctiva in Malawi. $B r f$ Ophthalmol 1979;63:102-9.

12 Tarlor HR. Aetiology of climatic droplet keratopathy and pterygium. Br f Ophthalmol 1980;64:154-63.

13 Hecht F. Familial hypersensitivity to insect stings. Lancet $1971 ;$ ii:469. 